\title{
Perancangan Sistem Kontrol Temperatur dan Kelembaban Tanah pada Rumah Kaca Berbasis Mikrokontroler Arduino Uno
}

\author{
Ayu Afifah Al-Farzaq*, Wildian \\ Laboratorium Elektronika dan Instrumentasi, Jurusan Fisika, \\ Fakultas Matematika dan Ilmu Pengetahuan Alam, Universitas Andalas \\ Kampus Unand Limau Manis, Padang, 25163, Indonesia* \\ *ayuafifah9489@gmail.com
}

\begin{abstract}
ABSTRAK
Telah dilakukan perancangan sistem kontrol temperatur dan kelembaban tanah pada rumah kaca berbasis mikrokontroler Arduino Uno. Sensor yang dipakai dalam penelitian ini yaitu sensor LM35 dan Soil Moisture YL-69 sebagai pendeteksi temperatur dan kelembaban tanah. Temperatur dan kelembaban yang terdeteksi ditampilkan pada LCD 2x16 karakter. Sistem kontrol menggunakan kontrol on/off untuk menghidup-matikan relai yang terhubung pada lampu pijar sebagai sumber panas, kipas sebagai pendingin dan pompa air untuk mengalirkan air pada penyiraman. Nilai temperatur yang diinginkan diatur dengan push button dan ditampilkan pada LCD. Uji akhir alat memperlihatkan bahwa alat ini mampu mengontrol temperatur dan kelembaban tanah di dalam rumah kaca. Rentang temperatur dan kelembaban tanah yang diuji berturut-turut adalah antara $27^{\circ} \mathrm{C}-31^{\circ} \mathrm{C}$ dan $10 \%-50 \%$.

Kata kunci: Rumah kaca, kontrol on/off, LM35, Soil Moisture YL-69, Arduino Uno
\end{abstract}

ABSTRACT

Design of temperature and soil moisture control system in greenhouse based on microcontroller Arduino Uno has been conducted. The system used LM35 and YL-69 type Soil Moisture sensor as a detector of temperature and soil moisture. Temperature and soil moisture value which were detected are displayed on the $2 x 16$ characters LCD. Control system using on-off control to switch on/off the relay which were connected to incandescent lamp as a heat source, fan as a cooler and water pump to drain the water in the watering. Desired temperature value is set by a push button, and this value is also displayed in the $L C D$. The final test shows that the system is able to control the temperature and soil moisture in greenhouse. The range of temperature and soil moisture were tested is between $27^{\circ} \mathrm{C}-31^{\circ} \mathrm{C}$ and $10 \%-50 \%$ respectively.

Keywords: Greenhouse, on-off control, LM35, Soil Moisture YL-69, Arduino Uno

\section{PENDAHULUAN}

Rumah kaca (greenhouse) merupakan suatu bangunan yang digunakan untuk budidaya tanaman. Stuktur bangunan rumah kaca dibuat menggunakan bahan yang tembus cahaya agar terbentuk iklim mikro di dalam rumah kaca yang berbeda dengan parameter iklim di sekitarnya. Terbentuknya iklim mikro di dalam rumah kaca ini terjadi karena radiasi cahaya tampak dari matahari yang masuk ke rumah kaca akan diubah menjadi radiasi inframerah yang sebagian tidak dapat keluar dari rumah kaca, sehingga temperatur di dalam rumah kaca menjadi lebih hangat. Tingginya temperatur di dalam dibandingkan dengan di luar rumah kaca inilah yang disebut sebagai efek rumah kaca (Bot, 1983). Terjaganya temperatur di dalam rumah kaca dibandingkan dengan sekitarnya membuat pertumbuhan tanaman yang ditanam di rumah kaca menjadi lebih optimal. Namun untuk daerah beriklim tropika basah seperti di Indonesia, tingginya temperatur udara di dalam rumah kaca dapat mencapai tingkat yang memicu stres pada tanaman. Tingginya kelembaban udara juga dapat mengganggu pertumbuhan tanaman karena merangsang pertumbuhan jamur yang menimbulkan penyakit pada tanaman (Alahudin, 2013).

Beberapa penelitian tentang teknologi rumah kaca telah dilakukan antara lain oleh Irawan (2011), yang membuat aplikasi fuzzy pada pengaturan rumah kaca tanaman dataran tinggi. Hasilnya pengaturan temperatur yang dikondisikan seperti dataran tinggi hanya bisa mencapai kisaran $25^{\circ} \mathrm{C}$ sampai $27^{\circ} \mathrm{C}$, nilai temperatur ini ditampilkan pada LCD dan komputer. Penelitian selanjutnya oleh Gunardi dan Firmansyah (2013), yang membuat sistem kontrol temperatur rumah kaca berbasis mikrokontroller AT89S51. Alat ini dapat mengontrol temperatur rumah kaca antara $31^{\circ} \mathrm{C}$ sampai dengan $38^{\circ} \mathrm{C}$, dan nilai temperaturnya ditampilkan di LCD. Penelitian lainnya oleh Naa dkk. (2015) yang membuat sebuah alat monitoring dan 
kontrol rumah kaca berbasis Arduino, LabView dan Antarmuka Web. Hasilnya alat yang dibuat dapat memonitoring nilai temperatur, kelembaban udara, kelembaban tanah, indeks UV, serta intensitas cahaya di dalam dan di luar rumah kaca dengan menggunakan 7 buah sensor. Data sensor dapat diamati secara offline dengan LabView.

Ketiga penelitian tersebut di atas menitikberatkan perancangan sistem yang ditujukan untuk pengontrolan temperatur tertentu yang tidak dapat diatur dan bekerja secara otomatis. Untuk itu, pada penelitian ini dibuat perancangan sistem kontrol temperatur dan kelembaban tanah pada rumah kaca berbasis mikrokontroler Arduino Uno. Rancangan alat ini menggunakan LM35 sebagai sensor temperatunya dan Soil Moisture sebagai sensor kelembaban tanahnya. Rentang temperatur dan kelembaban tanah yang diuji pada penelitian ini berturutturut adalah antara $27^{\circ} \mathrm{C}-31^{\circ} \mathrm{C}$ dan $10 \%-50 \%$. Perancangan ini diharapkan dapat menjadi alat bantu penelitian, konservasi tanaman dan praktikum di Jurusan Biologi dan Jurusan Pertanian.

\section{METODE}

\subsection{Alat dan Bahan}

Alat dan bahan yang digunakan dalam perancangan ini yaitu LM35, Soil Moisture YL69, mikrokontroler Arduino Uno, LCD 2 x 16, lampu pijar, kipas, pompa air, multimeter, termometer, moisturemeter, Personal Computer (PC), relai dan push button.

\subsection{Perancangan Diagram Blok Sistem}

Perancangan sistem kontrol temperatur dan kelembaban tanah pada rumah kaca terdiri dari rangkaian sensor temperatur (LM35), rangkaian sensor Soil Moisture, rangkaian sistem minimum mikrokontroler Arduino, rangkaian LCD dan rangkaian relai. Diagram blok dari perancangan sistem tersebut dapat dilihat pada Gambar 1.

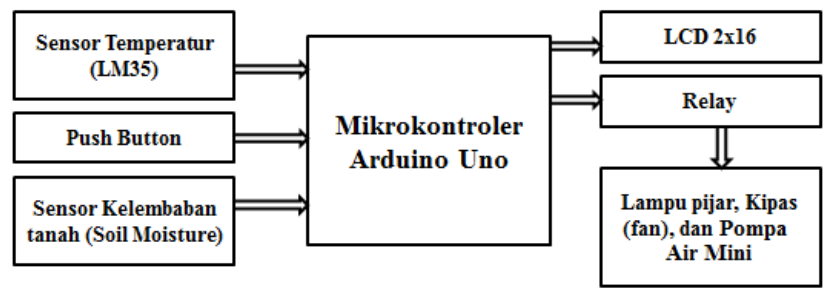

Gambar 1 Diagram blok sistem

\subsection{Perancangan Rangkaian Keseluruhan}

Sistem keseluruhan yang dibuat merupakan rangkaian yang akan digunakan agar sistem bekerja secara otomatis. Sistem otomatis ini akan dikontrol oleh kontrol utama mikrokontroler arduino uno yang akan disambungkan dengan sumber tegangan, sensor temperatur, sensor kelembaban, rangkaian push button, rangkaian relai dan rangkaian LCD 2x16. Pada penelitian ini dipakai dua mikrokontroler yang masing-masing untuk pengontrolan temperatur dan kelembaban tanah. Skema rangkaian untuk pengontrolan temperatur dapat dilihat pada Gambar 2 dan skema rangkaian untuk pengontrol kelembaban dapat dilihat pada Gambar 3.

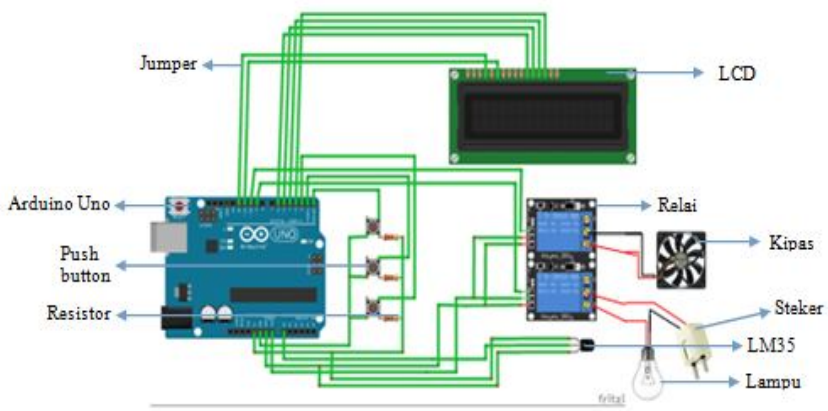

Gambar 2 Rangkaian sistem pengontrolan temperatur 


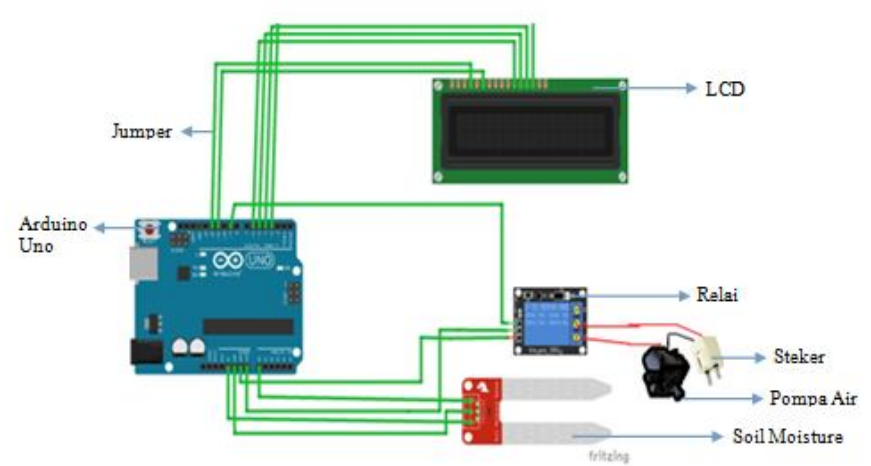

Gambar 3 Rangkaian sistem pengontrolan kelembaban tanah

\subsection{Perancangan Perangkat Lunak Sistem}

Program pada mikrokontroler Arduino Uno dibuat dengan menggunakan bahasa C. Algoritma program pengontrolan sistem yaitu:

1. Pada awal program, diberi input batas atas temperatur (Ta), batas bawah temperatur (Tb), batas atas kelembaban tanah $(\mathrm{Ka})$ dan batas bawah kelembaban tanah $(\mathrm{Kb})$.

2. Kemudian program membaca nilai temperatur dan kelembaban tanah yang terdeteksi oleh sensor LM35 dan Soil Moisture di dalam rumah kaca.

3. Nilai dari temperatur dan kelembaban tanah tersebut ditampilkan pada LCD.

4. Nilai $\mathrm{T}$ dibandingkan dengan nilai $\mathrm{Ta}$ dan $\mathrm{Tb}$, jika $\mathrm{T}$ lebih besar dibanding $\mathrm{Ta}$ maka program akan menyalakan kipas dan mematikan lampu melalui relai, jika $\mathrm{T}$ lebih kecil dibanding Tb maka program akan menyalakan lampu dan mematikan kipas, sedangkan jika $\mathrm{T}$ lebih kecil dari Ta dan lebih besar dari $\mathrm{Tb}$ maka program akan menyalakan kipas dan mematikan lampu.

5. Nilai $\mathrm{K}$ juga dibandingkan dengan $\mathrm{Ka}$ dan $\mathrm{Kb}$, jika nilai $\mathrm{K}$ lebih kecil dibandingkan $\mathrm{Kb}$ maka program akan mengaktifkan relai untuk menyalakan pompa yang mengalirkan air ke dalam rumah kaca, jika $\mathrm{K}$ lebih besar dari Ka maka program akan mematikan relai pada pompa air,sedangkan jika $\mathrm{K}$ lebih kecil dari Ka dan lebih besar dari $\mathrm{Kb}$ maka pompa air juga akan mati.

\section{HASIL DAN DISKUSI}

\subsection{Hasil Rancangan Alat}

Sistem kontrol temperatur dan kelembaban tanah pada rumah kaca yang telah dibuat dapat dilihat pada Gambar 4. Perancangan rumah kaca ini terdiri dari rangkaian sistem minimum mikrokontroler Arduino, LCD, rangkaian push button, rangkaian relai, LM35, Soil Moisture, lampu pijar, kipas dan pompa air.

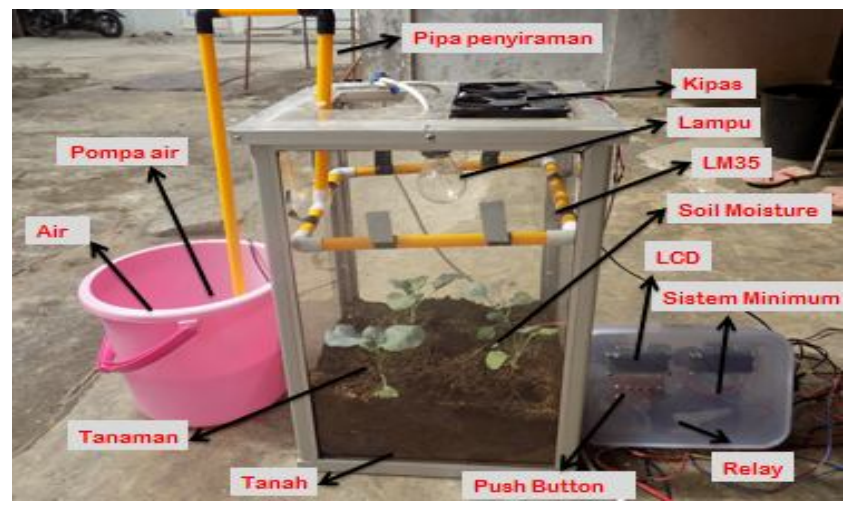

Gambar 4 Hasil rancangan alat

\subsection{Hasil Pengujian Sensor LM35}

Pengujian sensor LM35 dilakukan dengan melihat perbandingan antara nilai temperatur yang terbaca pada termometer digital dengan nilai tegangan keluaran pada sensor. Tegangan 
keluaran pada sensor ini dilihat menggunakan multimeter digital. Hasil perbandingan nilai tersebut dapat dilihat pada Gambar 5.

Pada Gambar 5 didapatkan fungsi transfer dari hasil perbandingan antara tegangan keluaran sensor dengan nilai temperatur yaitu $y=9,6939 x+10,428$. Fungsi transfer ini menunjukkan bahwa sensitivitas sensor adalah sebesar 9,6939 dan memiliki nilai tegangan offset sebesar 10,428. Nilai regresi yang dihasilkan sensor mendekati 1 yaitu sebesar 0,9962. Nilai ini sudah menunjukkan bahwa hubungan antara tegangan keluaran sensor dengan nilai temperatur pada alat ukur adalah linier.

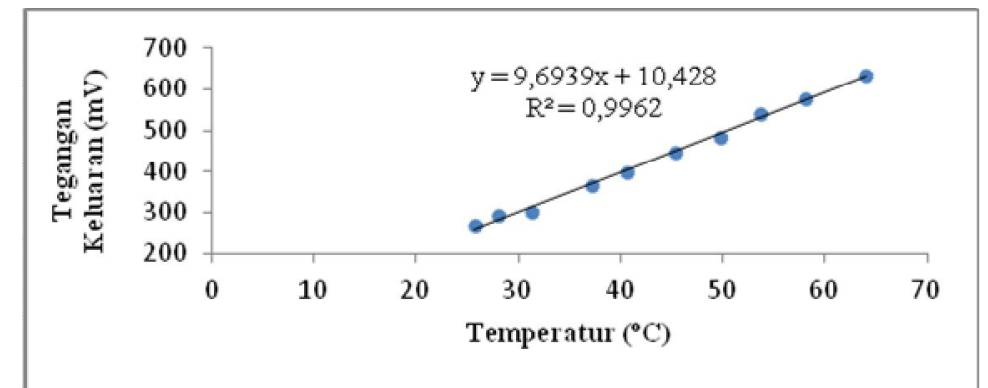

Gambar 5 Hubungan temperatur dengan tegangan keluaran LM35

\subsection{Hasil Pengujian Sensor Soil Moisture YL-69}

Pengujian sensor Soil Moisture dilakukan dengan memberikan beberapa variasi nilai volume air pada tanah dengan massa $300 \mathrm{~g}$. Data tegangan keluaran sensor diambil menggunakan multimeter digital dan data kelembaban tanah didapatkan dari alat ukur kelembaban tanah yaitu Moisture Meter Lutron MS-7003. Teknis pengambilan data dilakukan pada sampel tanah yang sama. Hasil perbandingan data tegangan keluaran sensor dengan nilai kelembaban tanah tersebut dapat dilihat pada Gambar 6.

Berdasarkan Gambar 6 didapatkan hasil fungsi transfer antara tegangan keluaran sensor Soil Moisture dengan nilai kelembaban tanah pada alat ukur yaitu $y=0,03581 x+$ 0,9736 dimana $x$ merupakan nilai kelembaban tanah dan $y$ adalah keluaran dari sensor kelembaban tanah. Hasil derajat kolerasi linier yang didapatkan yaitu sebesar 0,9862, nilai ini sudah menunjukkan bahwa hubungan antara tegangan keluaran sensor dengan nilai kelembaban tanah pada alat ukur adalah linier.

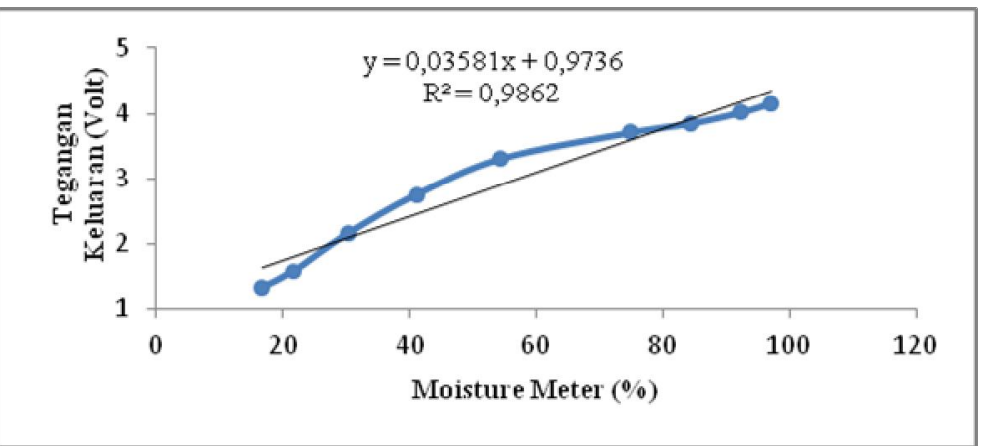

Gambar 6 Hubungan kelembaban tanah dengan tegangan keluaran Soil Moisture

\subsection{Hasil Pengujian Lampu Pijar Sebagai Pemanas}

Pengujian sumber pemanas (lampu pijar) dilakukan dengan membandingkan nilai temperatur yang dihasilkan di dalam model rumah kaca dengan menyalakan lampu pijar terhadap waktu. Temperatur awal di dalam rumah kaca ini yaitu sebesar $29,2^{\circ} \mathrm{C}$ dan temperatur lingkungan sebesar $27,7^{\circ} \mathrm{C}$. Pemanasan dilakukan dengan menggunaan 2 buah lampu pijar dan data temperatur pemanasan dicatat setiap 2 menit.Hasil perbandingan antara temperatur di dalam rumah kaca terhadap waktu tersebut dapat dilihat pada Gambar 7.

Berdasarkan Gambar 7 dapat dilihat bahwa temperatur di dalam rumah kaca bertambah karena pemanasan oleh lampu pijar hingga sebesar $35,45^{\circ} \mathrm{C}$. Setelah pemanasan selama 24 menit temperatur tidak mengalami pertambahan lagi. Dari data yang didapatkan tersebut dapat 
disimpulkan bahwa dengan menggunakan 2 buah lampu pijar dengan daya 60 watt temperatur dari $29,2^{\circ} \mathrm{C}$ naik hingga $35,5^{\circ} \mathrm{C}$ dalam waktu 24 menit. Kenaikan temperatur ini menunjukkan bahwa lampu pijar sudah dapat digunakan sebagai sumber pemanas di dalam rumah kaca.

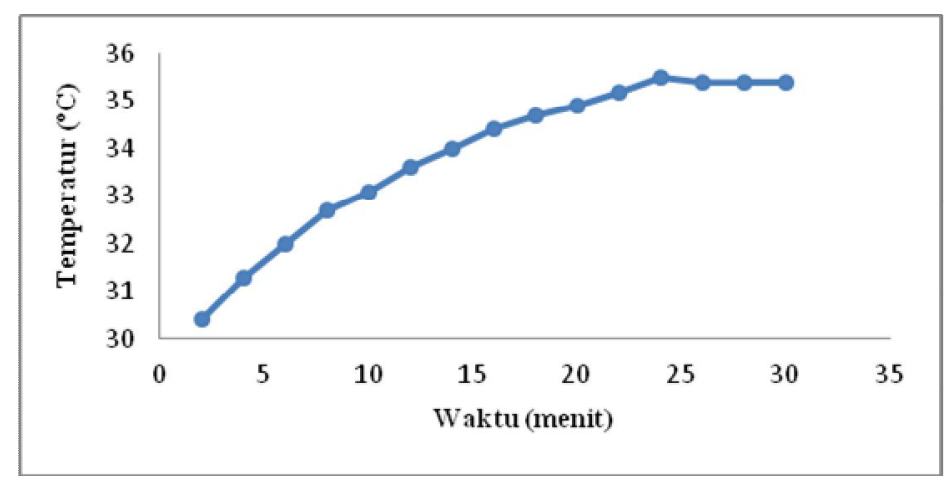

Gambar 7 Hubungan antara temperatur pemanasan dengan waktu

\subsection{Hasil Pengujian Kipas Sebagai Pendingin}

Pengujian sumber pendingin (kipas/fan) dilakukan juga dengan membandingkan nilai temperatur yang dihasilkan di dalam model rumah kaca dengan menyalakan kipas terhadap waktu. Temperatur awal di dalam rumah kaca ini yaitu sebesar $31,5^{\circ} \mathrm{C}$ dan temperatur lingkungan sebesar $27,8^{\circ} \mathrm{C}$. Nilai data temperatur pendinginan dicatat setiap 2 menit. Hasil perbandingan antara temperatur di dalam rumah kaca terhadap waktu tersebut dapat dilihat pada Gambar 8.

Berdasarkan Gambar 8 dapat dilihat bahwa temperatur di dalam rumah kaca berkurang karena pendinginan oleh kipas dari temperatur $31,5^{\circ} \mathrm{C}$ hingga temperatur $24,7^{\circ} \mathrm{C}$. Setelah pendinginan selama 44 menit temperatur tidak mengalami pertambahan lagi. Dari data yang didapatkan tersebut dapat disimpulkan bahwa kipas sudah dapat digunakan sebagai sumber pendingin di dalam rumah kaca karena kipas mampu menurunkan temperatur hingga $24,7^{\circ} \mathrm{C}$.

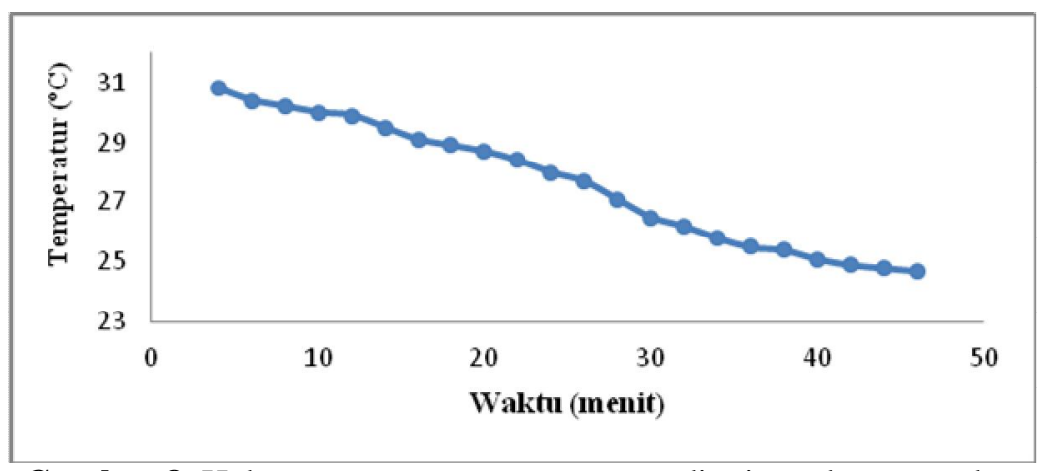

Gambar 8 Hubungan antara temperatur pendinginan dengan waktu

\subsection{Hasil Pengujian Sistem Kontrol Temperatur}

Sistem kontrol yang digunakan pada penelitian ini adalah sistem kontrol on/off . Dalam pengoperasiannya sistem kontrol on/off menggunakan rangkaian relai sebagai saklar. Pada pengujian kontrol temperatur ini data yang diambil yaitu $28^{\circ} \mathrm{C}$, dan hasil pengujian dapat dilihat pada Gambar 9.

Berdasarkan Gambar 9 pengaturan temperatur yang diatur dengan push button adalah $28^{\circ} \mathrm{C}$ sebagai temperatur acuan, sedangkan temperatur awal di dalam model rumah kaca yaitu $26^{\circ} \mathrm{C}$. Saat sistem kontrol aktif maka lampu pijar akan menyala untuk menaikkan temperatur sampai $31^{\circ} \mathrm{C}$. Namun jika temperatur yang terdeteksi diatas $31^{\circ} \mathrm{C}$ maka lampu pijar akan mati dan kipas akan aktif untuk menurunkan temperatur sampai temperatur $27^{\circ} \mathrm{C}$. Sistem kontrol ini dapat menjaga kestabilan temperatur antara $27^{\circ} \mathrm{C}-31^{\circ} \mathrm{C}$ selama 22 menit. 


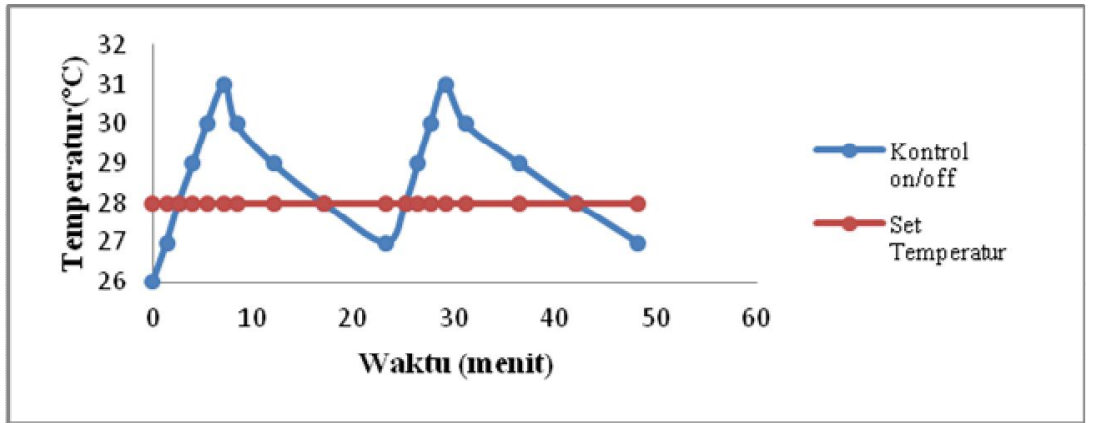

Gambar 9 Hasil pengujian kontrol temperatur

\subsection{Hasil Pengujian Sistem Kontrol Kelembaban Tanah}

Pengujian sistem kontrol kelembaban tanah pada penelitian ini menggunakan sistem kontrol on/off untuk menghidup-matikan relai yang terhubung pada pompa air. Pengujian ini bertujuan untuk melihat apakah pengontrolan terhadap kelembaban tanah sudah berjalan dengan baik. Pada pengujian data yang diambil yaitu antara $10 \%$ dengan $50 \%$. Hasil pengujian dapat dilihat pada Gambar 10.

Berdasarkan Gambar 10 dapat dilihat bahwa kelembaban tanah akan turun seiring berjalannya waktu sehingga perlu dilakukan pengontrolan agar kelembaban tanah tetap terjaga. Pengontrolan ini dilakukan dengan mengaktifkan relai pada pompa air saat nilai kelembaban tanah berada di bawah $10 \%$ dan menonaktifkan relai kembali saat nilai kelembaban tanah telah berada di atas 50\%. Pada pengujian ini dapat dilihat bahwa sistem kontrol sudah bekerja dengan baik.

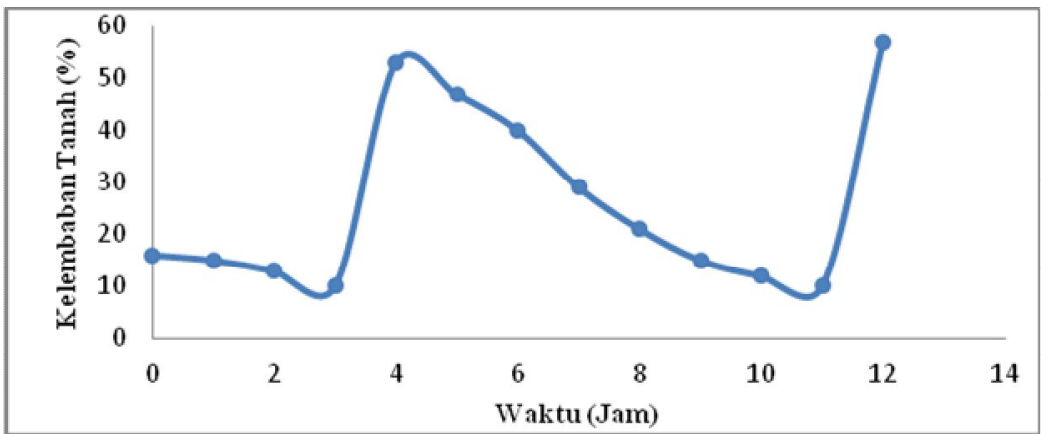

Gambar 10 Hasil pengujian kontrol kelembaban tanah

\section{KESIMPULAN}

Perancangan sistem kontrol tempratur dan kelembaban tanah pada rumah kaca berbasis Arduino Uno dengan LM35 sebagai sensor temperaturnya dan Soil Moisture YL-69 sebagai sensor kelembaban tanahnya telah berhasil dilakukan. Perancangan alat ini telah berhasil mengontrol temperatur antara $27^{\circ} \mathrm{C}-31^{\circ} \mathrm{C}$ dan kelembaban tanah antara $10 \%-50 \%$.

\section{DAFTAR PUSTAKA}

Alahudin, M., Kondisi Termal Bangunan Greenhouse dan Screenhouse pada Fakultas Pertanian Univesitas Musamus Merauke, Jurnal Ilmiah Mustek Anim Ha Vol.2 No.1 (2013), hal. 16-27.

Bot, G.P.A., Greenhouse Climate: from Physical Processes to a Dynamic Model, Thesis, Agricultural University of Wageningen, The Netherlands, 1983.

Gunardi, Y. dan Firmansyah, Perancangan Kontrol Otomatis Temperatur Rumah Kaca Berbasis Mikrokontroler AT89S51, Jurnal Teknik Elektro, Universitas Mercu Buana (2013), hal. 142-150.

Irawan D.S., Aplikasi Fuzzy pada Pengaturan Rumah Kaca Tanaman Dataran Tinggi, Jurnal Ilmiah PENS-ITS (2011), hal. 1-7.

Naa, C.F. dkk., Sistem Monitoring dan Kontrol Rumah Kaca berbasis Arduino, LabView, dan Antarmuka Web, Jurnal SKF (2015), hal.65-72. 